\title{
Say Yes or No to Antibiotics During Endodontic Treatment- A Dilemma
}

\author{
Dr. Pradnya V. Bansode ${ }^{1}$,Dr. Seema D. Pathak ${ }^{2}$,Dr. M. B. Wavdhane ${ }^{3}$, \\ Dr. S. B. Khedgikar ${ }^{4}$,Dr. Reshma Sakharkar ${ }^{5}$ \\ 1-Professor and Head Of Department Of Conservative Dentistry and Endodontics, \\ 2-Asso. Professor, 3-Asso. Professor 4-Assit Professor, 5-Post Graduate Student \\ Govt Dental College \& Hosp, Aurangabad
}

\begin{abstract}
Antibiotics are commonly used in dental practice. Many dental practitioners prescribe the antibiotics to prevent possible development of pain and swelling. This is being done more out of tradition rather than any sound scientific base. This overuse of antibiotics which is leading to the emergence of antibiotic resistant bacterial strains is a global concern. Being an Endodontist or even a Dental Surgeon, it is imperative that one must stress the importance of appropriate endodontic intervention in all the involved cases, with oral antibiotic administration used only as an adjunct. Moreover, one must be aware of all the pros and cons of antibiotic therapy and of course, the very fact that whether they are needed or not in a particular case in the first place. The purpose of this paper is to enlighten the dental fraternity about the true rationale behind advocating the antibiotics during endodontic interventions.
\end{abstract}

Keywords : antibiotics, endodontic intervention

\section{Introduction}

Dental infections may be successfully treated by the removal of the source of the infection; this may require drainage of an associated abscess and removal of the infected pulp canal contents, or, by extracting the tooth. Endodontics is largely concerned with the treatment of infections originating in the root canal system. Antibiotics have been used extensively for the management of Odontogenic infections since their discovery early in past century. The term antibiotic was coined by Waksman in 1942 and was defined as a substance produced by micro-organisms, or a synthetic derivative of a naturally occurring substance, that inhibits the growth or causes death of other micro-organisms. In spite of all its myriad advantages, the irony remains that antibiotics constitute the single most abused group of drugs in health care today. This has lead to an alarming increase in the rate of microbial resistance to antibiotics.

The basic principle of management of infections suggest that an antibiotic should only be used to supplement, and not to substitute, the conventional surgical methods. Systematic antibiotics should be used with restraint because of the possibilities of allergic reactions, toxicity, side effects and development of resistant strains of microbs. Being the life saving drugs and as therapeutic agents, the role and value of antibiotics in the field of Dentistry to curb dental and oral infections is indeed inestimable [1]. Nevertheless, certain misconceptions and notions regarding their usage in the clinical practice of Endodontics have culminated into undesirable sequel and end results. There prevails a common notion and misbelieve like heavy doses of any broad spectrum antibiotic or last generation antibiotics can heal any kind of endodontic infection and hence, may postpone or retard the very requirement of an endodontic procedure. Such assumptions, too often not only result in antibiotic abuse but terminate into drastic consequences like persistence or proliferation of existing problem, severe, acute exacerbation of chronic infections, development of resistant strain, drug toxicity, allergic and hypersensitivity reactions, photo toxicity etc. In all the endodontic pathologies, be pulpal or periapical, some are infected yet few others are only inflammatory lesions [2]. Hence, elimination of irritants, especially pathogenic bacteria from the pulp space or root canal by careful and appropriate endodontic procedures is far more effective therapy over prescribing solely oral antibiotics and recommending no elective dental treatment in a particular case. Through this article we will discuss the rationale of antibiotics and outline the recommendation of for use and choice of antibiotics.

\section{Rationale Of Antibiotics}

Rational use of antibiotics is extremely important as injudicious use can adversely affect the patient, cause emergence of antibiotic resistance and increase the cost of health care. Prescribing an antibiotic comprises several phases:

1. Perception of need: is an antibiotic necessary?

2. Choice of antibiotic : what is the most appropriate antibiotic? 
3. Choice of regimen: what dose, route, frequency and duration are needed?

4. Monitoring efficacy: is the treatment effective?

\section{A Are antibiotics necessary?}

Antibiotics are generally only useful for the treatment of bacterial infections. It is important to remember that not all fevers are due to infections and not all infections are caused by bacteria. The majority of infections seen in general practice are of viral origin and antibiotics can neither treat viral infections nor prevent secondary bacterial infections in these patients. Even where a bacterial aetiology is established, an antibiotic may not be always necessary. Many bacterial infections resolve spontaneously. Minor superficial skin infections may be more suitably treated with a local antiseptic. Collections of pus should be drained surgically and if drainage is adequate, antibiotics are often not required.

\section{Indications Of Antibiotics}

Antibiotic are not an alternative to dental intervention; they are adjunct [3],[4]. Antibiotics are indicated when clinical signs of involvement are evident. The major use of antibiotic prophylaxis for dental procedures, are cases which cause bleeding in the oral cavity, has become a common practice among dentists [5]. Antibiotics are indicated in dental practice for treating immune-compromised patients, evident signs of systemic infection and if the signs and symptoms of infection progress rapidly [6].

\section{A Antibiotics During Root Canal Treatment}

The risk of adverse effects following systemic application and the ineffectiveness of systemic antibiotics in some pulpal and periapical conditions has led to the use of locally applied antibiotics in root canal treatment, that is within the canal system (Mohammadi \& Abbott 2009) [7]. The first reported locally used antibiotic product was a polyantibiotic paste containing penicillin, bacitracin, streptomycin and caprylate sodium (Grossman 1951) [8]. Taking into account that endodontic infections are polymicrobial, tetracyclines (tetracycline $\mathrm{HCl}$, minocycline, demeclocycline, doxycycline), a group of broad spectrum antibiotics that are effective against a wide range of microorganisms, have been proposed as intracanal topical antibiotics. Sato et al. (1996) demonstrated the penetration through dentine and the antibacterial efficacy of a mixture of minocycline, a tetracycline, with ciprofloxacin and metronidazole, placed in root canals previously irrigated ultrasonically [9].

Molander et al. (1990) demonstrated that intracanal clindamycin offers no advantage over conventional calcium hydroxide root canal dressing [10]. BioPure MTAD (Dentsply Sirona, Salzburg, Austria), a mixture of doxycycline, citric acid and a detergent (Tween 80), has been proposed as a final irrigant because of its numerous properties: antimicrobial activity, smear layer- and pulp-dissolving capability, effect on dentine and adhesion, and biocompatibility (Torabinejad et al. 2003)[11]. However, microorganisms isolated from root canals have resistance against this group of antibiotics (Jungermann et al. 2001, Sku_cait_e et al. 2010, AlAhmad et al. 2014), and tetracyclines may promote fungal growth (MacNeill et al. 1997) [12,13,14,15]. Abbott et al. (1990) demonstrated that when placed in the root canal, the concentration and effectiveness of $3.2 \%$ demeclocycline (Ledermix, Lederle Pharmaceuticals, Wolfratshausen, Germany) were significantly reduced in peripheral dentine and in the apical third over time [16]. In addition to limited antimicrobial activity, tetracyclines another commercial product for intracanal use(Abbott et al. 1990) [17]. It contains two antibiotics, neomycin and polymyxin B sulphate, but the effect against endodontic flora is not better than with calcium hydroxide (Tang et al. 2004, Chu et al. 2006) [18,19]. The use of topical antibiotics in root canal treatment has also been proposed to prevent or reduce postoperative symptoms. However, antibiotics do not reduce the pain or swelling arising from teeth with symptomatic apical pathosis (Keenan et al. 2006, Cope et al. 2014) [20,21]. In summary, use of topical antibiotics during root canal treatment is not supported by the evidence.

\section{III.B Prophylaxis of focal infection}

The use of antibiotics as prophylaxis for focal infection is common practice, and has been widely accepted in the dental profession. The paradigm of this model of treatment is the prevention of bacterial endocarditis, indicated in risk patients in the context of any invasive procedure within the oral cavity and following the guidelines of the American Health Association (AHA) [22].

Nevertheless, there are doubts in relation to this practice. Firstly, transient bacteremia occurs not only after dental treatments such as extractions $(35-80 \%)$ or periodontal surgery $(30-88 \%)$. It also occurs in the context of tooth brushing (40\%) or while chewing gum $(20 \%)$, and is proportional to the trauma caused and to the number of germs colonizing the affected zone. Secondly, not only bacteria cause endocarditis, and of those that do cause the disease, many are resistant to the antibiotics administered as prophylaxis (fundamentally amoxicillin). Lastly, it is known that most cases of bacterial endocarditis are not related with invasive procedures, and that dental care is only responsible for a minimum percentage of cases of the disease. 
Despite the mentioned inconveniences, antibiotic prophylaxis is still recommended in patients at risk [23]. However, the results of a survey conducted by Tomas-Carmona et al. on the knowledge and approach to the prevention of bacterial endocarditis among Spanish dentists showed that fewer than $30 \%$ of the professionals were aware of correct antibiotic indications and posology [24]. There is no scientific basis for recommending systematic antibiotic prophylaxis prior to invasive dental treatment in patients with total joint prostheses [25]. Jacobson published a study on 2693 patients with total joint replacement (hip or knee). In 30 of the patients he detected infection of the prosthesis, and in only one case was a time relationship with prior dental treatment established. Furthermore, 54\% of the germs isolated were Staphylococcus aureus and epidermidis [26]. According to the American Dental Association and the American Academy of Orthopedic Surgeons, evaluation is required of antibiotic prophylaxis in patients with total joint prostheses in the presence of immune deficiency, when contemplating high risk dental procedures in patients with prostheses in place for less than two years, and in patients who have already suffered past joint prosthesis infections [27]. Most infections are usually controlled with appropriate antibiotics in 7-10 days. If a diffused periapical swelling caused by an endodontic infection does not show any remission in 3-5 days during treatment with antibiotics, bacterial culture of root canal and antibiotic sensitivity test are highly recommended.

\section{Conclusion}

Since their discovery many decades ago, safe systemic antibiotics have revolutionized the treatment of infections, transforming once deadly diseases into manageable health problems. However, the growing phenomenon of bacterial resistance, caused by the use and abuse of antibiotics and the simultaneous decline in research and development of new antimicrobial drugs, is now threatening to take us back to the pre-antibiotic era. The dental profession has an obligation to limit the use of antibiotics to those situations that actually require them and to situation where patients will benefit from their use. They should not be used as pain relief medications in the absence of local dental treatment. Antibiotics will not help to resolve pulpitis, they will not prevent post-operative pain or flare-ups. Patients, dentists and doctors need to be educated and diligent about the role of antibiotics and the long term consequences of their misuse and abuse.

\section{Acknowledgment}

We wish to thank Dean, Dr. S. P. Dange, for his support and able guidance.

\section{References}

[1]. Holroyd SV. Clinical pharmacology of antibiotics of dental importance, Dent. Clin. North Am. 1970; 14:697

[2]. Gopikrishna and Parmeshwaran. Role of antibiotics in Endodontics J. Ind. Dent. Assoc. 2001:69-71

[3]. Pallasch TJ. Antibiotics in endodontics. Dent Clin North America. 1979;23:737-746. [PubMed]

[4]. Abbott PV, Hume WR, Pearrmar JW. Antibiotics and endodontics. Australian Dent J. 1990;35:50-60.[PubMed]

[5]. Tong DC, Rothwell BR. Antibiotic prophylaxsis in dentistry. A review and practice recommendation. JADA. 2000;131:366374. [PubMed]

[6]. Henry M, Al Reader, Beck M. Effect of Penicillin in post-operative endodontic pain and swelling in symptomatic necrotic teeth. J Endodontics. 2001;27(2):117-123. [PubMed]

[7]. Mohammadi Z, Abbott PV (2009) Antimicrobial substantivity of root canal irrigants and medicament: a review. Australian Endodontic Journal 35, 131-39.

[8]. Grossman LI (1951) Polyantibiotic treatment of pulplessmteeth. Journal of American Dental Association 43, 265-78.

[9]. Sato I, Ando-Kurihara N, Kota K et al. (1996) Sterilization of infected root-canal dentine by topical application of a mixture of ciprofloxacin, metronidazole and minocycline in situ. International Endodontic Journal 29, 118-24.

[10]. Molander A, Reit C, Dahl_en G (1990) Microbiological evaluation of clindamycin as a root canal dressing in teeth with apical periodontitis. International Endodontic Journal 23, 113-8.

[11]. Torabinejad M, Khademi AA, Babagoli J et al. (2003) A new solution for the removal of the smear layer. Journal of Endodontics $29,170-5$.

[12]. Jungermann GB, Burns K, Nandakumar R, Tolba M, Venezia RA, Fouad AF (2001) Antibiotic resistance in primary and persistent endodontic infections. Journal of Endodontics 37, 1337-44.

[13]. Sku_cait_e N, Pe ciulien_e V, Manelien e R, Ma ciulskien_e V (2010) Antibiotic prescription for the treatment of endodontic pathology: a survey among Lithuanian dentists.

[14]. Medicina 46, 806-13.

[15]. Al-Ahmad A, Ameen H, Pelz K et al. (2014) Antibiotic resistance and capacity for biofilm formation of different bacteria isolated from endodontic infections associated with

[16]. root-filled teeth. Journal of Endodontics 40, 223-30.

[17]. MacNeill S, Rindler E, Walker A, Brown AR, Cobb CM (1997) Effects of tetracycline hydrochloride and chlorhexidine gluconate on Candida albicans. An in vitro study. Journal of Clinical Periodontology 24, 753-60.

[18]. Abbott PV (2000) Selective and intelligent use of antibiotics in endodontics. Australian Endodontic Journal 26, 30-9.

[19]. Abbott PV, Hume WR, Pearman JW (1990) Antibiotics and endodontics. Australian Dental Journal 3, 50-60.

[20]. Tang G, Samaranayake LP, Yip HK (2004) Molecular evaluation of residual endodontic microorganisms after instrumentation, irrigation and medication with either calcium

[21]. hydroxide or Septomixine. Oral Diseases 10, 389-97.

[22]. Chu FC, Leung WK, Tsang PC, Chow TW, Samaranayake LP (2006) Identification of cultivable microorganisms from root canals with apical periodontitis following two-visit endodontic treatment with antibiotics/steroid or calcium hydroxide dressings. Journal of Endodontics 32, 17-23. 
[23]. Keenan JV, Farman AG, Fedorowicz Z, Newton JT (2006) A Cochrane systematic review finds no evidence to support the use of antibiotics for pain relief in irreversible pulpitis.

[24]. Journal of Endodontics 32, 87-92.

[25]. Cope A, Francis N, Wood F, Mann MK, Chestnutt IG (2014) Systemic antibiotics for symptomatic apical periodontitis and acute apical abscess in adults. Cochrane Database Systematic Reviews (6) CD010136.

[26]. Dajani AS, Taubert KA, Wilson W, Bolger AF, Bayer A, Ferrieri P, et al .Prevention of bacterial endocarditis: recommendations by the American Heart Association. J Am Dent Assoc 1997;128:1142-51.

[27]. ADA. Terapéutica Dental. Barcelona:Masson; 2003. p. 596-600

[28]. Tomas Carmona I, Diz Dios P, Limeres Posse J, Outumuro Rial M, Caamano Duran F, Fernandez Feijoo J, et al. Chemoprophylaxis of bacterial endocarditis recommended by general dental practitioners in Spain. Med Oral 2004;9:56-62.

[29]. Pallasch TJ, Slots J. Antibiotic prophylaxis and the medically compromised patient. Periodontol 2000 1996;10:107-38.

[30]. Jacobson JJ, Millard HD, Plezia R, Blankenship JR. Dental treatment and late prosthetic joint infections. Oral Surg Oral Med Oral Pathol 1986;61:413-7.

[31]. American Dental Association; American Academy of Orthopedic Surgeons. Antibiotic prophylaxis for dental patients with total joint replacements. J Am Dent Assoc 2003;134:895-9. 